\title{
EL USO DE LOS CATECISMO EN \\ LA ENSEÑANZA DE LA RELIGIÓN CATÓLICA EN EL PERÍODO NEOGRANADINO Y DE LOS ESTADOS UNIDOS DE COLOMBIA 1831-1886
}

\author{
Jorge Enrique Duarte Acero ${ }^{1}$ \\ Universidad Pedagógica y Tecnológica de Colombia-Colombia \\ Grupo de investigación HISULA \\ jorge.duarte@uptc.edu.co \\ Martha Consuelo Riveros Bonilla ${ }^{2}$ \\ Universidad Colegio Mayor de Cundinamarca-Colombia \\ consueloriverosbon@hotmail.com
}

Recepción: 27/03/2011

Evaluación: 25/05/2011

Aceptación: 22/06/2011

Artículo de Reflexión

\section{RESUMEN}

Este artículo es el resultado de una investigación sobre el proyecto "La enseñanza de la Religión Católica, en el siglo XIX en la Nueva Granada y de los Estados Unidos de Colombia". Se ofrece una reseña, descripción y análisis sobre los principales catecismos, algunos fueron autorizados por el Presidente del Estado Soberano (Cundinamarca 1882), otros por el Arzobispo de Santa Fe de Bogotá (Monseñor Manuel José Mosquera 1843) y después de la Constitución Política de 1886, y del Concordato de 1887, el Arzobispo de Santa Fe de Bogotá Monseñor José Telesforo Paúl S.J. (1886) y Monseñor Bernardo Herrera (1896). El objetivo principal del estudio es señalar la participación directa de los sacerdotes de la Compañía de Jesús (los Jesuitas) en la construcción del proyecto educativo católico del siglo XIX, la dirección del seminario

\footnotetext{
${ }^{1}$ Estudios de Licenciatura de Administración de la Educación, Especialista en Gerencia Educativa, Magíster en Investigación y Docencia Universitaria y Candidato a Doctor del Doctorado en Ciencias de la Educación- RUDECOLOMBIA, integrante del grupo de investigación Historia y prospectiva de la Universidad Latinoamericana- HISULA. Licenciatura en Administración Educativa, Especialista en Pedagogía y Ética, Magíster en Administración y Supervisión Educativa. Ponente Internacional área: Historia de los Colegios Mayores de Cultura Femenina en Colombia 1945-1995, integrante del grupo de investigación: Pedagogía y Andragogía -Universidad Colegio Mayor de Cundinamarca.
} 
Colegio de San Bartolomé, de colegios, autoría de los principales catecismos, de la evangelización y en el ejercicio de ser los Arzobispos de Santafé de Bogotá.

Palabras clave: Revista Historia de la Educación Latinoamericana, catecismos, textos religiosos, enseñanza religiosa, educación católica.

\title{
THE USE OF CATECHISMS IN TEACHING CATHOLIC RELIGION IN THE NEW-GRANADINO PERIOD AND IN THE UNITED STATES OF COLOMBIA 1831-1886
}

\author{
Jorge Enrique Duarte Acero \\ Universidad Pedagógica y Tecnológica de Colombia- Colombia \\ Research Group HISULA \\ jorge.duarte@uptc.edu.co \\ Martha Consuelo Riveros Bonilla \\ Universidad Colegio Mayor de Cundinamarca-Colombia \\ consueloriverosbon@botmail.com
}

\begin{abstract}
This article is the result of a research on the project " The teaching of Catholic Religion in in the XIX century in the Nueva Granada and in the United States of Colombia". it offers a review, a description and analysis about the main cathecisms. Some of them were authorized by the President from the Sovereign State (Cundinamarca 1882), and others by the Archibishop from Santa Fe de Bogotá (Monsignor Manuel José Mosquera 1843), and after the Political Constitution of 1886 and the concordat of 1987, the Archibishop from Santa Fe de Bogotá Monsignor José Telesforo Paúl S.J. (1886) and Monsignor Bernardo Herrera (1896). The main objective of this study is pointing out the direct participation of priests from the Jesus Company (The Jesuits), in the construction of a Catholic Educative Project of XIX century as well as the direction of seminario Colegio de San Bartolomé, schools owned by the authorship of main cathecisms, evangelization and the practice of being the Archibishops from Santa Fe de Bogotá.
\end{abstract}

Key words: Journal of Latin American Education History, catechisms', religious texts, religious teaching and catholic education. 


\title{
O USO DO CATECISMO NO ENSINO DA RELIGIÃO CATÓLICA NO PERÍODO NEOGRANADINO E DOS ESTADOS UNIDOS DA COLÔMBIA 1831-1886
}

\author{
Jorge Enrique Duarte Acero \\ Universidade Pedagógica e Tecnológica de Colômbia- Colômbia \\ Grupo de pesquisa HISULA \\ jorge.duarte@uptc.edu.co \\ Martha Consuelo Riveros Bonilla \\ Universidade Colégio Maior de Cundinamarca-Colômbia \\ consueloriverosbon@hotmail.com
}

\begin{abstract}
RESUMO
Este artigo é resultado de uma pesquisa sobre o projeto "O ensino da Religião Católica no século XIX na Nova Granada e nos Estados Unidos da Colômbia". Oferece-se uma resenha, descrição e análise sobre os principais catecismos, alguns foram autorizados pelo presidente do Estado Soberano (Cundinamarca, 1882), outros pelo Arcebispo de Santa Fé de Bogotá (Monsenhor Manuel José Mosquera, 1843) e depois da Constituição Política de 1886, e do Concordato de 1887, o Arcebispo de Santa Fé de Bogotá, Monsenhor José Telesforo Paúl S.J. (1886) e Monsenhor Bernardo Herrera (1896). O objetivo principal do estudo é assinalar a participação direta dos sacerdotes da Companhia de Jesus (os jesuítas) na construção do projeto educativo católico do século XIX, a direção do seminário Colégio de São Bartolomeu, de colégios, autoria dos principais catecismos, da evangelização e no exercício de ser os Arcebispos de Santafé de Bogotá.
\end{abstract}

Palavras-chave: Revista História da Educação Latino-americana, catecismos, textos religiosos, ensino religioso, educação católica. 


\section{INTRODUCCIÓN}

La investigación es de tipo documental, se realizó desde fuentes primarias; los catecismos documentos originales, los archivos de la Biblioteca Nacional de Colombia - Fondos Especiales: Samper y Quijano Caballero; del Fondo Pedagógico y Fondo Posada de la Universidad Pedagógica y Tecnológica de Colombia; de la Biblioteca "Luis Ángel Arango". Las Memorias de los Ministros de Instrucción Pública. El Diario Oficial y del Archivo General de la Nación. Este trabajo, es una apretada síntesis del proyecto de investigación incluye siete epígrafes que dan respuesta a los siguientes interrogantes: ¿Cuál fue el contexto político y religioso de la Nueva Granadas y los Estados Unidos de Colombia? ¿Cuáles fueron las características de la educación católica en el período de la Regeneración? ¿Cuáles normas señalan la obligatoriedad de los textos en la enseñanza de la religión? ¿Cuál fue la metodología escritural de los catecismos? y ¿Cuáles fueron los principales catecismos utilizados en la enseñanza de la religión?

1. Una aproximación al contexto político y religioso de la Nueva Granada 1831-1857 y de los Estados Unidos de Colombia 1861-1885

El contexto político y religioso de la Nueva Granada (1831-1857) y de los Estados Unidos de Colombia (1861-1885) estuvo centrado por la llegada al país en 1844 de la Compañía de Jesús y su misión de evangelización, fundación de Colegios y enseñanza de la Doctrina Cristiana a través de textos, llamados catecismos, entre ellos el del P. Astete. Dos Presidentes liberales 1850 y 1863, decidieron la expulsión de los Jesuitas, y por ende de las Comunidades Religiosas de nuestro país. Sin embargo la Nación Colombiana registró, durante este período diversas guerras civiles; dos Constituciones Políticas 1831 y 1863; el funcionamiento de ocho Estados Soberanos Federales, de educación laica, del régimen liberal radical.

La Nueva Granada, es el período de Gobierno de 1831 a 1857; que nace de la celebración del Congreso Constituyente de 1831, en la Iglesia de San Ignacio (de la Compañía de Jesús), que eligió Presidente al Doctor José Ignacio de Márquez. El 17 de noviembre de 1831 se expidió, la Ley Fundamental de la Nueva Granada por la cual las Provincias del Centro de la Antigua Colombia, formaron un Estado con el nombre de Nueva 
Granada. La nueva Constitución, sancionada el 29 de febrero de 1832, fue expedida:

En el nombre de Dios, Autor y Supremo legislador del universo". En ella prevalecen los principios del liberalismo moderado; las libertades públicas se limitan racionalmente; se acata la tolerancia religiosa e impone al Gobierno la obligación de proteger a los granadinos en el ejercicio de la Religión católica, Apostólica y Romana; se debilita el Poder Ejecutivo en tiempos de pazy se le dan grandes prerrogativas para el tiempo de guerra.

En la Nueva Granada, la llamada "Reforma instruccionista" del Presidente Pedro Alcántara Herrán (1841-1845), la instrucción pública contó con la cooperación eficaz del Doctor Ospina Rodríguez, Secretario de lo Interior (Gobierno). Merced al nuevo plan de estudios, pudo formarse en las Universidades una generación brillante y se multiplicaron los colegios y las Escuelas Normales en las Provincias. Los alumnos fueron sometidos a una rigurosa disciplina. El Doctor Ospina, en 1842, bajo "elpretexto de catequizary reducir las tribus salvajes de nuestro suelo, presentó ante el Congreso un proyecto de Ley "Sobre el establecimiento de uno o más colegios de Misiones en la República" autorizando al Ejecutivo para que eligiera "el Instituto que juzgase más aparente. Europa profesa el ministerio de las misiones". La idea del Doctor Ospina, era la de traer a los sacerdotes de la Compañía de Jesús. Hubo en el Congreso discusiones agitadísimas; sometido a votación el proyecto paso a las Cámaras, y por Decreto del Ejecutivo de mayo 3 de 1842, la Compañía de Jesús, fue designada para fundar los Colegios de Misiones. En 1844, los Jesuitas asumieron la Dirección del Seminario Colegio de San Bartolomé y restauraron la obra de evangelización del Caquetá; el Padre José Segundo Lainez fue el autor de esta gloriosa epopeya.

El $1^{\circ}$ de abril de 1849 asumió la Presidencia el General José Hilario López. Entre sus reformas administrativas, están el abolir la pena de muerte por delitos políticos, establecer el juicio por jurados en materia criminal, dar libertad de imprenta, descentralizar las rentas para dar mayor autonomía administrativa a las Provincias, y declarar libre la

${ }^{3}$ GRANADOS, Rafael María. (1963): S.J. Historia de Colombia. La Independencia y la República. Texto adaptado al Programa Oficial de sexto año. Novena edición. Medellín, Editorial Bedout, p. 292. 
exportación de oro en polvo o en barras; el mérito principal, fue "el abolir de la esclavitud en nuestra Patria". López sancionó la ley de 21 de mayo de 1851 sobre libertad de los esclavos. "Desde el $1^{\circ}$ de enero de 1852 serán libres todos los esclavos que existan en el territorio de la República" art.1․ Mayores de 30 años, el número ascendía a unos veintiséis mil. La ley de 15 de mayo de 1850, sobre Instrucción pública dispuso: "Es libre en la República la enseñanza en todos los ramos, de las Ciencias, las letras y de las artes. El grado o título científico no será necesario para ejercer profesiones científicas; pero podrán obtenerlo las personas que lo quieran. Para ejercer la profesión de Farmaceuta se necesita obtener la aprobación de los exámenes. Suprímese el grado de bachiller. Suprímense las Universidades...Para optar grados no es necesario haber estudiado en los colegios nacionales o provinciales $\mathrm{o}$ en seminario.

El 21 de mayo de 1850, el General López autorizó, la primera expulsión de los Jesuitas. Después de publicada la providencia del Gobierno, daba a los Miembros de la Compañía de Jesús, el término de cuarenta y ocho horas para la partida, la cual se efectuó a las dos de la mañana del 24 del mismo mes. Una cruda persecución religiosa que causó herida profunda al sentimiento cristiano de la mayoría de los granadinos: la autoridad espiritual quedó sometida al juicio de los Tribunales civiles, se abolieron los diezmos y el fuero eclesiástico. Los Consejos Municipales y los cabildos quedaron autorizados para nombrar los Párrocos de las poblaciones sin intervención de los Obispos; se disponían de los bienes del culto y se decretaban los gastos. En resumen, la Iglesia quedó sometida al poder civil; al protestar los Prelados, fueron desterrados, entre ellos el Arzobispo de Bogotá, Manuel José Mosquera y los Obispos de Cartagena y de Pamplona.

La ley de 9 de febrero de 1863 "que organiza provisoriamente, el gobierno de la Unión Colombiana", dispone, que mientras se expide la Constitución Política, el gobierno Ejecutivo estará a cargo de un Ministerio compuesto por cinco Ministros de lo Interior, de Relaciones Exteriores, de Hacienda, del Tesoro y de Guerra. El 8 de mayo de 1863 es promulgada Constitución de Rionegro. Se le coloca a la Nación el nombre de Estados Unidos de Colombia, el cual rigió hasta 1885. Se borró del Preámbulo de la Constitución, el Nombre Dios; hecho nunca hasta 
entonces visto en los actos legislativos de nuestra historia y señalándose, las libertades absolutas de prensa y de palabra. El principio establecer un sistema federal dando plena soberanía a cada uno de los nueve Estados: Antioquia, Boyacá, Bolívar, Cauca, Cundinamarca, Magdalena, Panamá, Santander y Tolima. El liberalismo Radical, gobierna la Nación, con los principios de la educación laica; "federación y libertad" y, "Ciencia y Progreso". La filosofía positivista, la filosofía utilitarista, y la instrucción popular. En lo eclesiástico, el Gobierno de los Estados Soberanos, ejercía "la inspección de cultos" y ordenaba prohibir la adquisición de bienes a las Comunidades religiosas. Señala dos años para el ejercicio del Poder Ejecutivo, que inicia el $1^{\circ}$ de abril.

El Presidente General Tomás Cipriano de Mosquera (18611863) desde el inicio de su gobierno realizó una obra devastadora de persecución religiosa; ordena la expulsión de los Jesuitas (la segunda) y de las Comunidades religiosas en 1863. El General Mosquera obligo a la separación Iglesia - Estado y la libertad para todos los cultos. Expidió el decreto sobre tuición de Cultos, según el cual, ningún Sacerdote podía desempeñar los Ministerios sagrados sin el permiso del Gobierno, so pena de destierro del país (julio 20). "El 26 de julio, el Presidente Mosquera declaró disuelta la Compañía de Jesús, ordenó la ocupación de sus bienes y que salieran del país, el 9 de septiembre dio la providencia sobre desamortización de bienes de manos muertas. El 3 de noviembre da prisión del Arzobispo Ilmo. Señor Doctor Antonio Herrán y por el decreto del 5 de noviembre, "extinción" de todos los Conventos, monasterios y casas de religiosos, acabando con una tradición de más de 300 años".

El Presidente Eustorgio Salgar (1870-1872) y el Secretario de Instrucción Pública Dámaso Zapata, el $1^{\circ}$ de noviembre de 1870 promulgaron el Decreto Orgánico de Instrucción Pública. Nace la práctica, "suprimir la enseñanza religiosa en las escuelas". La administración Salgar fue progresista, cambio y mejoró la instrucción pública; fundó las Escuelas Normales y trajo maestros extranjeros para dirigirlas (La Primera Misión Pedagógica Alemana 1872). Entre los ideólogos de la Educación están: Pestalozzi Juan E.; Horacio Mann y

\footnotetext{
${ }^{4}$ GRANADOS, Rafael María. (1963): S.J. Historia de Colombia. La Independencia y la República. Texto adaptado al Programa Oficial de sexto año. Novena edición. Medellín, Editorial Bedout, p. 292.
} 
Herbert Spencer. Al General Sergio Camargo, de mayo a agosto de 1877, le correspondió terminar el período del Presidente Aquileo Parra (18761878). Al comienzo de su mandato favoreció las relaciones Iglesia-Estado; autorizó la enseñanza de la religión en los establecimientos oficiales y permitió a los alumnos su participación en ceremonias religiosas, dentro de su horario de clases. El General Camargo, restableció la $P A Z$ RELIGIOS A y consiguió un acercamiento entre los partidos políticos a raíz de la guerra civil de 1876, la llamada guerra de las escuelas. Durante los 23 años de vigencia de la Constitución de Rionegro, sus efectos fueron desastrosos, dos guerras civiles, más de 40 revoluciones entre los Estados Soberanos y dos conflictos con Ecuador (1862 y 1863).

\section{La educación católica en el período de la República de Colombia 1886-1898}

En el estudio de la Historia de la Educación Colombiana del Siglo XIX es significativa la utilización de catecismos para la enseñanza de la religión católica. Sin embargo, se piensa que por la Constitución Política de 1886 y el Concordato de 1887, se dio a los catecismos el reconocimiento legal, pero todos los catecismos, en este período de investigación historiográfica, ya poseían la autorización del Arzobispo de Santafé de Bogotá o del Presidente del Estado Soberano, definido como. Imprimatur + Bernardus A.S.". Después de la guerra civil de 1885 (liberales del Gobierno y conservadores por fuera de él) nace el período de la "Regeneración" o la Hegemonía Conservadora, 1886 a 1904. Se crea el proyecto político "La Educación Católica Oficial” vigente hasta 1930 con la aplicación de los principios tradicionales, la filosofía escolástica, el Teocentrismo y el Cristocentrismo (Del Concilio Vaticano II de 1870), el "Educar al hombre inculcando la Verdad y combatiendo el error". "Ir por el mundo y predicad el evangelio, la buena nueva". La creación de Universidades en Bogotá y la definición de un Programa académico oficial para la religión y la moral de acuerdo con un catecismo señalan, la construcción del pensamiento católico del siglo XIX en la nueva República de Colombia de 1886, que es el nombre actual.

Las reformas educativas de 1886, 1888, 1892 y de 1903, reconocen como obligatoria la enseñanza de la religión católica, especifican a través de resoluciones o de circulares el nombre de los Catecismos y textos de religión o de la Doctrina Cristiana con los cuales se enseña la religión. En 
1884 se funda la Universidad Católica de Bogotá, Doctor Carlos Martínez Silva y Monseñor Juan Bautista Agnozzi, tendría como sede el Colegio del Espíritu Santo. El sábado 01 de marzo de 1884 abrió sus puertas la Universidad Católica de Bogotá con 200 estudiantes y las Facultades de Filosofía y Letras; Ciencias Naturales, Ingeniería y Jurisprudencia que finaliza sus actividades académicas en 1890.

En 1886 se crea la Universidad Externado de Colombia en Bogotá con el nombre de Universidad Externado de Derecho de Colombia, "el lunes 15 de febrero, para la formación del pensamiento y la ideología liberal, por los Doctores Nicolás Pinzón Warlosten, Diego Mendoza Pérez; Salvador Camacho Roldán, Santiago Pérez y Francisco de Paula Borda”. El Ministerio de la Instrucción Pública creó la Revista de la Instrucción Pública y la revista Anales de la Instrucción Pública. La Ley 61 de 1888, "Ley de caballos", afirma: la Prensa será libre en tiempo de Paz, responsable, honra de las personas, se garantizan las libertades individuales".

\section{Un acercamiento al concepto de Catecismo}

La definición más pertinente sobre Catecismo corresponde al padre Lasalde Carlos (1922) quien señala la importancia de éste y de cómo se enseña con él, y de la necesidad de aprender las sentencias y no las palabras. Se afirma que todos los catecismos enseñan la misma doctrina, varían algo en su exposición. "El Catecismo es un compendio de la ley divina, tal como Jesucristo se la enseñó a sus apóstoles y como éstos, inspirados por el Espíritu Santo, la predicaron al mundo. De modo que sabiendo el catecismo se viene en conocimiento de la ley divina y se entra en el camino de la salvación, pues para guardar la ley es preciso conocerla. El catecismo enseña la ley divina bajo ciertas fórmulas. Aunque todos los catecismos enseñan la misma doctrina, varían algo en su exposición; es regla general que en cada diócesis no se admita sino un solo catecismo, con objeto de que los fieles todos de la diócesis aprendan su doctrina con las mismas palabras. No son ciertamente las palabras lo que se trata de aprender, sino las sentencias; pero es indudable que, lo mismo en doctrina cristiana que en todas las ciencias, contribuye mucho a aprender y retener fácilmente lo aprendido, si esto se expresa siempre 
con la misma fórmula. Basta para dar a conocer la importancia de saber el catecismo recordar las palabras del Salvador a sus apóstoles: "Predicad el Evangelio a toda criatura; el que creyere y fuere bautizado será salvo; pero el que no creyere será condenado. Marcos XVI, 16"5.

Diversas advertencias se hace el P. Lasalde Carlos (1922) para la enseñanza con el catecismo, entre ellas: "1-La enseñanza de la doctrina cristiana, siguiendo la marcha del catecismo, es muy difícil para los niños, sobre todo en los grados inferior y medio. 2-La razón de los niños no está suficientemente desarrollada, ni hay en ellos los conocimientos necesarios para comprender las verdades profundas de la Religión que se contienen en muchas preguntas del Catecismo. 3-Las historias bíblicas son casos concretos de las lecciones del catecismo, por lo que éstas deben ser deducidas de aquéllas y enlazadas con ellas. 4-La enseñanza propiamente dicha del catecismo no debe darse a los niños de grado inferior sino indirectamente, accidentalmente digamos así, derivada de las historias bíblicas. 5- El catecismo servirá como auxiliar para que los niños estudien en casa lo explicado en la escuela. En el grado medio aprenderán las respuestas del catecismo en la clase por impresión y 6-Cada lección ha de formar un todo que no se debe dividir"”.

Para el Sacerdote Jesuita F.X. Schouppe, S.J. (1883) "Cuando la enseñanza religiosa se limita a los primeros rudimentos de la doctrina cristiana, y se contenta con imprimir en la memoria de los niños su conocimiento exacto, se llama Catecismo, curso de religión primaria o inferior; cuando se eleva hasta la ciencia propiamente dicha, o sea el conocimiento razonado de las verdades religiosas, se llama curso superior de religión”.

Finalmente, el catecismo es el compendio de la ley divina, tal como Jesucristo se la enseñó a sus apóstoles y como éstos, inspirados por el Espíritu Santo, la predicaron al mundo. Corresponde a los prelados de la Iglesia católica enseñar la religión, la doctrina cristiana y la historia sagrada y como enseñanzas se encuentra en los catecismos, muchos de los cuales fueron ampliamente utilizados en los Colegios, seminarios y Universidades de la Nueva Granada y los Estados Unidos de Colombia, durante el siglo XIX.

${ }^{5}$ LASALDE, Carlos. (1922): Manual de Pedagogía o sea exposición de los principios fundamentales de la educación y de los métodos de enseñanza. 2a.edición con el retrato del autor Docente de las Escuelas Pías. Friburgo de Brisgovia (Alemania). Herder \& Cía. Libreros Editores Pontificios. Berlín, p. 233.

LASALDE, Carlos. (1922): óp., cit, p. 287. 


\section{De la obligatoriedad de los textos enseñanza de la religión a partir de 1886}

En la Resolución 595 de 1886, el Ministro de Instrucción Pública José Domingo Ospina establece la obligatoriedad de los textos escolares para la enseñanza de la religión y los deberes de los Directores de Escuela "Hacer los mayores esfuerzos para elevar el sentimiento moral y religioso de los niños confiados a su cuidado e instrucción y grabar en sus corazones los principios de piedad, justicia, respeto a la verdad, amor a su patria y en suma, todas las virtudes que son el ornamento de la especie humana y la base sobre la que reposa toda sociedad civilizada y libre" Art.16. "En todas las Escuelas, asi normales como primarias, se enseñará la religión católica. Los textos que sirvan para la enseñanza de la religión, serán los aprobados para este efecto por la respectiva autoridad eclesiástica. Caso de que el cura Párroco le manifieste al Director de escuela voluntad de dar la enseñanza religiosa, aquel será el encargado de ella; pero el Director suplirá sus faltas en los días en que no ocurra a la hora señalada en la distribución del tiempo. La enseñanza religiosa será sometida a la vigilancia de los Párrocos" Art.25 De los métodos de enseñanza: "En la designación de los métodos de enseñanza, el Ministerio de Instrucción Pública deberá tener por base las siguientes reglas:-1. La Exposición ha de ser sencilla, lógica y correcta;- 2. No se adoptará ningún método que tienda a producir el resultado de desarrollar la memoria a expensas del entendimiento ni inculcar a los niños un saber puramente mecánico;- 3. Debe tenerse presente que la inteligencia de los niños ha de cultivarse siguiendo una senda tal, que los ponga en aptitud de descubrir por sí mismos las reglas, los motivos y los principios de lo que se aprende" art. 38 y "Las materias de enseñanza "Se dividirán en cursos progresivos, distribuidos de manera que los niños los recorran gradualmente en los años que dure el aprendizaje; sin que sea permitido hacer alteración a favor de ningún individuo, ni dar la preferencia a una materia sobre otra, ni entrar en operaciones forzadas del espíritu, contrarias al desarrollo natural de la razón Art. 39",

Según el Reglamento de las Escuelas Primarias, "Entre los métodos generales que el Maestro puede poner en práctica, los principales son: el socrático, el de puntos o preguntas o erotemático, el de conversación

7 DECRETO 595 DE 1886 (9 de octubre) Por el cual se organiza la Instrucción Pública Primaria. El Ministro de Instrucción Pública José Domingo Ospina. El Presidente J. M. Campo Serrano. Diario Oficial No. 6830 de 1886. pp. 1146 al 1151. 
y el auditivo y sintético. El método Socrático consiste en hacer hábiles preguntas al discípulo para conducirle a descubrir por sí mismo la verdad. El maestro lo dirige sin violencia, haciendo que él exponga sus propias ideas; si éstas son exactas, el maestro las fija por medio de oportunos ejemplos; si son erróneas, se le hace ver claro el absurdo para que él descubra sus legítimas consecuencias" Art. $26^{8}$.

\section{Metodología escritural del catecismo para la enseñanza de la religión}

Las principales metodologías utilizadas en la escritura de los catecismos para la enseñanza de la Religión son: la mayéutica, la catequesis y el método objetivo pestaloziano.

-La mayéutica de Sócrates es el método en la enseñanza de sus teorías. El diálogo, la ironía, la "maieutica", la inducción, la sintesis y la deducción. En seis pasos: "el primero, lleva al interlocutor de pregunta en pregunta al conocimiento de la verdad; por la segunda, haciendo fina chanza de las opiniones de sus adversarios, los conducía de un modo progresivo a la adopción de sus propios puntos de vista; por la tercera, aludiendo al oficio de su madre, ayudaba las mentes de los demás a dar a luz la ciencia; por la cuarta, de casos particulares subía a ideas generales; por la quinta, reducía lo múltiple a la unidad, lo complejo a lo simple, a lo universal; y por la sexta, desciende de lo general-universal a cosas particulares, a elementos lógicos que desarrolla, a principios metafísicos que él supone, sin salir del orden de verdades morales". La tarea Socrática de hacer mejores a los demás, propugna por un conocimiento de sí mismo; de persuadir a cada joven a buscar la virtud y la sabiduría, y que antes de andar procurando el acrecentamiento del interés particular, se debe mirar el interés de la ciudad, señalando que éste es el orden que debe observarse siempre en todas las acciones. Su método integra la ironía, la mayéutica y la dialéctica. Mediante la ironía del "sólo sé que nada sé", fustiga y cuestiona mediante la mayéutica, saca a luz llevando a primer

plano la discusión de los problemas fundamentales del hombre; mediante la dialéctica, este arte de preguntar inteligente logra la determinación

\footnotetext{
${ }^{8}$ Reglamento para las Escuelas Primarias. Título VIII. Tratado I. Instrucción Pública Primaria. 31 de julio de 1893. Imprenta de La Luz. Bogotá, p. 47.

${ }^{8}$ PÉREZ, José María. (1941): Catecismo de la historia de la Filosofía. Edit. San Juan Eudes.

Usaquén-Cundinamarca. Bogotá, 4 de diciembre, p. 33.
} 
esencial del hombre" ${ }^{10}$-El Principio de la enseñanza socrática. Todo buen maestro debe estar en estado de sacar, por medio de preguntas sobre toda especie de asuntos religiosos y morales, de los niños respuestas justas y precisas. "A los jóvenes enseñaba con imágenes intuitivas, y daban a las mayores nociones claras por medio de la enseñanza socrática. Los libros de enseñanza no deben ser otra cosa que un medio de enlazar artificialmente la enseñanza, en cada uno de los ramos. Ellos no deben ser más que una preparación artificial de las fuerzas que son necesarias al hombre para utilizar con seguridad lo que la naturaleza misma hace para el desarrollo de él" ".

- La Catequesis (método) es un método de instrucción a través de preguntas y respuestas que los alumnos deben aprender de memoria y luego repetir o recitar de acuerdo con lo enseñado por el Catequista. Se denomina catequesis "el instruir"; la instrucción de temas propios de una religión, especialmente del cristianismo. La peculiaridad de la catequesis distinta del primer anuncio del Evangelio que ha suscitado la conversión, persigue el doble objetivo de hacer madurar la fe inicial y de educar al verdadero discípulo de un conocimiento más profundo y sistemático de la persona y del mensaje de Nuestro Señor Jesucristo. Según el Catecismo de la Iglesia católica Numeral 5 dice: "La catequesis es una educación en la fe de los niños, de los jóvenes y de los adultos que comprende una enseñanza de la doctrina dada generalmente de modo orgánico y sistemático con miras a iniciarlos en la vida cristiana". Se llamó catequesis al conjunto de los esfuerzos realizados de la Iglesia para hacer discípulos, para ayudar a los hombres a creer que Jesús es el Hijo de Dios a fin de que por la fe, tengan vida en su nombre y para educarlos e instruirlos en esta vida y construir así el Cuerpo de Cristo. Durante la catequesis, el catequista enseña a los alumnos las preguntas del catecismo. Generalmente se realiza como preparación a la Primera Comunión, en caso de la Iglesia Católica ${ }^{12}$.

-El método Objetivo Pestalozziano. La enseñanza objetiva o intuitiva. El Decreto 255 de 1886 (enero 13) "Por el cual se organiza provisionalmente la instrucción Pública Primaria”. El método de enseñanza será el Pestalozziano Objetivo, para los estudios científicos. La exposición ha de ser sencilla, lógica y correcta; se procurará siempre que no se produzca

\footnotetext{
${ }^{10}$ SOPÓ, Ángel María. (2002): Antropología Filosófica. Unidad 3. La Antropología filosófica en su bistoria. Bogotá, Ed. USTA, VUAD, $3^{\text {a }}$ reimpresión, pp. 81-82.

${ }_{12}^{11}$ Ibídem., pp. 284-286.

http.es.wikipedia.org.wiki.catequesis. www.teología.com
} 
el resultado de desarrollar la memoria a expensas del entendimiento" Art. 7 y "La enseñanza de las Escuelas no se limitará a la instrucción, sino que comprenderá el desarrollo armónico de todas las facultades del alma, de los sentidos y de las fuerzas del cuerpo" Art. $8^{13}$. Pestalozzi fundaba su método en un acuerdo perfecto con la marcha de la naturaleza y no puso en él más arte que el que es necesario para permitir a esta ejercer en el espíritu del hombre la acción que reclama esencialmente el desarrollo de sus facultades. Fue base del método de Pestalozzi la formación de las madres para educar a sus hijos. "El objeto esencial del método de Pestalozzi era devolver la madre al niño y poner en manos de la primera una serie de procedimientos para unir el corazón de ambos. Conducir a los hombres por medio de su método a poder ayudarse a sí mismos, porque a ellos sobre esta tierra de Dios nadie ayuda y nadie puede ayudar . En Bogotá en 1893, el método objetivo, fue utilizado: -"Para la enseñanza de la religión, utilizar el método natural, llamado por los Institutores de la provincia de Guatavita "Objetivo" combinado con la repetición oral y el catequístico. Para mantener la disciplina, que el Director se gane la buena voluntad de los niños y las constantes visitas del Inspector inquieran sobre este asunto. La coincidencia de los maestros en la necesidad de utilizar el método "Objetivo" se convirtió en un supuesto generalizado en aquella época. Por ello, aunque Pestalozzi había sido conocido y difundido desde mucho tiempo atrás, a finales del Siglo era un prestigio declararse partidario de su pedagogía. No en vano el Colegio Pestalozziano de Eva Gooding, era el que más alumnos enseñaba entre todos los particulares que había en Bogotá" ${ }^{15}$.

\section{Los catecismos y textos en la enseñanza de la religión}

El marco de referencia para la investigación responde al mensaje Arzobispo de Bogotá, José Telésforo Paul, S.J. sobre la obligatoriedad de los catecismos que deben ser utilizados en las Escuelas Elementales, en

\footnotetext{
${ }^{13}$ DECRETO 255 DE 1886 (enero 13) Por el cual se organiza provisionalmente la instrucción Pública Primaria. Miguel Casabianca Gobernador Civil y Militar del Estado del Tolima. Neiva. 13 enero de 1886. Adriano Tribin, Secretario de Gobierno. Diario Oficial N. 6586 del martes 2 de febrero de 1886. Año XXII, pp. 110-111.

${ }^{14}$ BLANCO Y SÁNCHEZ, Rufino. (1909): Pestalozzi su vida y su obra. El sistema. El método Pestalozzi - Pestalozzi en España. Madrid (E). Imprenta de la Revista de ARCHIVOS. Infantos 42 bajo.

${ }^{5}$ VAHOS VEGA, Luis Arturo. (2002): La Reforma Educativa de 1893: epílogo de una estrategia. Historia de la Educación en Bogotá. Tomo I. Bogotá, Panamericana Formas e Impresos, p. 304.
} 
las Escuelas Superiores y en los Institutos de Educación Secundaria, en cumplimiento a lo ordenado por el Concordato de 1887. "Primeramente, estos textos son los siguientes: 1. Los textos Catecismos para las escuelas elementales, 2: Los maestros y 3. Las prácticas religiosas.

Textos escuelas elementales.-"El Catecismo del Padre Gaspar Astete adicionado por el Ilustrísimo señor Mosquera.-"Pequeño Curso de Historia Sagrada de don Federico Justo Ruecht, traducido por don Vicente Ortiz y Escolano. ESCUELAS SUPERIORES. -"Exposición demostrada de la Doctrina Cristiana" por el señor Presbítero Don Juan Buenaventura Ortiz" y la Historia Sagrada de don José Joaquín Ortiz. INSTITUTOS DE EDUCACIÓN SECUNDARIA.-Curso abreviado de Religión por el Reverendo Padre X. Schouppe, traducido al castellano por don Manuel Pérez Villamil.

En cuanto a los maestros señala que las clases deben ser dictadas por los señores curas que en caso de ausencia podrán dictar los maestros cumpliendo con normas propias de la religión y la moral y desarrollar los programas sobre religión y moral.

"Los Maestros". Las clases deben darlas, no los señores curas, sino los maestros. Primero porque muchos de ellos tienen tan extensas parroquias que su administración, si no del todo, sí les impide el enseñar con regularidad en las escuelas. Segundo y principalmente, porque a los Maestros que se respeten y quieran ser respetados por los niños, les será imposible expresarse contra la religión, puesto que la enseñan y no podrán, sin caer en ridículo, mostrarse en contradicción defendiendo y atacando una misma doctrina".

Para las prácticas religiosas señala el Arzobispo el cumplimiento de la Semana Santa de los Sacramentos, de los Mandamientos y de las oraciones en las escuelas públicas:

Las Prácticas Religiosas. 1. Anualmente en el Colegio del Rosario y demás Colegios Universitarios hará un retiro que será de tres días; y estos servirán para el cumplimiento pascual; y deberán hacerse en la primera o segunda semana de Cuaresma. 2.- En los colegios de niños y niñas de 8 a 14 años, deberá haber tres (3) confesiones en el año, que deberán hacerse en fiestas principales, poniéndose de acuerdo para ello los maestros y los 
párrocos. 3.- Diariamente se rezará en comunidad en todos los colegios de internos las oraciones de la mañana, el Rosario de cinco misterios antes del refresco de la noche, y antes de acostarse las oraciones apropiadas. Al comenzar el estudio y todas las clases se rezará esta invocación: “Trono de la sabiduría, rogad por nosotros" seguida de un Avemaría. 4.- En las Escuelas Públicas Primarias se observarán las mismas prácticas que en la Universidad, con dos (2) diferencias: a) No habrá recitación del Rosario; b) En vez de las oraciones de la mañana y de la noche se cantarán al entrar en la escuela y salir de ella, los himnos junto con las oraciones de que se habla antes" $"$

El Ministro de Instrucción Pública, Jesús Casas Rojas, por Resolución del 15 de junio de 1888 y en cumplimiento a lo preceptuado en el Art. $4^{\circ}$ del Decreto 544 de 1888, señalando como obligatorio lo anteriormente mencionado por el Arzobispo José Telésforo Paul:

El Ministro de Instrucción Pública, Liborio Zerda, 1893, en el Art. 82 del Decreto 429 de 1893 (20 de enero) estableció los textos para la enseñanza de las materias morales y religiosas así: "Los textos de enseñanza serán designados por el Gobierno, de acuerdo con los Directores y Catedráticos. Para la enseñanza de materias morales y religiosas, serán elegidos textos de autores católicos, y para ser adoptados precederá aprobación del Ilmo. Sr. Arzobispo de Bogotá, con arreglo al Concordato. Caso de que el Cura Párroco le manifieste al maestro de la Escuela voluntad de dar la enseñanza religiosa, aquél será encargado de ella; pero el Director suplirá sus faltas. La enseñanza de la religión estará sometida a la vigilancia de los Párrocos." Art. $9^{\mathrm{o}^{17}}$.

El Ministro de Instrucción Pública, por resolución del 19 de agosto de 1887, aprobó los textos adoptados por los Padres de la Compañía de Jesús del Colegio de San Bartolomé para la enseñanza de las materias que constituyen los cursos de la Facultad de Filosofía y letras de la Universidad Nacional. Los textos son los siguientes:- Religión Schouppe.- Gramática Castellana - La Academia,- Gramática Latina - La Cerda o Miguel,- Geografía - Martínez Silva,-Historia Sagrada

${ }^{16}$ P. JOSÉ TELÉSFORO PAUL, S.J. (1888): Mensaje del Arzobispo de Bogotá dirigido al Sr. Ministro de Instrucción Pública Jesús César Rojas, sobre los textos para la enseñanza de la Religión Católica. 4 de junio de 1888.

DECRETO 429 DE 1893 (20 DE ENERO) por el cual se organiza la Instrucción Pública primaria. Diario Oficial No. 9.073 Bogotá, domingo 12 de febrero de 1893, pp. 195-199. 
- Ortiz Buenaventura,- Historia Patria - Borda,-- Historia Universal Castro,- Retórica y Poética - Álvarez, - Aritmética - Rueda,- Álgebra - Cardin,- Geometría y Trigonometría -Cardin, -Filosofía -Libérate, - Física - Ganot, - Francés - Alm.,-Inglés -Robertson. Ministro José Domingo Ospina C."

Para concluir el Arzobispo de Bogotá José Telésforo Paul, SJ, y el Ministro de Instrucción Pública Jesús Casas Rojas, establecieron a través de resolución los Catecismos para la enseñanza de la religión, los requisitos para ser maestro de religión y moral, como también las prácticas religiosas que se deben cumplir a diario.

\section{Los principales catecismos utilizados para la enseñanza de la religión durante el período neogranadino y de los estados unidos de Colombia}

A continuación se hace una descripción general de los catecismos utilizados para la enseñanza de la religión de acuerdo con la estructura del libro, portada y carátula, tabla, prólogo, lecciones, preguntas y respuestas.

\section{Título de la obra: catecismo histórico del abad Claude Fleuri - 1824}

Para instrucción de los Niños, con preguntas, respuestas y lecciones seguidas para leerlas en las Escuelas. Compuesto POR EL ABAD FLEURY y traducido del FRANCÉS para utilidad de la tierna juventud. Reimpreso en Bogotá en la de José Manuel Galagarza. Año de 1824, 109 pág.

Estructura del libro:

1. Tabla del pequeño catecismo histórico

2. Prólogo

3. Partes y secciones

4. Preguntas y respuestas

\footnotetext{
${ }^{18}$ Resolución Agosto 19 de 1887. Ministro de Instrucción Pública J. Domingo Ospina C. Diario Oficial N. 7150 del sábado 27 agosto de 1887. Año XXIII, p. 964.
} 
- Tabla del pequeño Catecismo bistórico: Estructurado en dos (2) partes cada una de las cuales se desarrolla a través de lecciones. La primera: contiene sumariamente la Historia Sagrada y la segunda, la Doctrina Cristiana.

- Prólogo: Explica de cómo enseñar las lecciones. Estos enunciados permiten exponer los conceptos sobre la Historia Sagrada y Doctrina Cristiana.

- Partes y secciones: Dividida la primera parte Historia Sagrada en veintinueve lecciones, que cubrían entre otros los temas de la creación, el pecado del primer hombre, el diluvio, la ley natural, Abraham y los Patriarcas, el viaje del desierto, la ley escrita, la Alianza de Dios con los Israelitas, la Idolatría, David y del Mesías, los Profetas, los Judíos después del cautiverio, del Nacimiento de Jesús Christo, de San Juan Bautista , los enemigos de Jesús Christo, la pasión de Jesu Christo, el Espíritu Santo ,los Apóstoles, la destrucción de Jerusalén. La segunda parte la Doctrina Cristiana en veintinueve lecciones de la Fe, la Esperanza y la Caridad, la Encarnación del Verbo, el descenso de Jesús Christo a los infiernos, de su resurrección y su ascensión, la oración dominical, los Mandamientos de la Iglesia, los Sacramentos, el bautismo, la confirmación, la penitencia, la extremaunción","19

Este texto se utilizó la enseñanza de la Religión y de la Historia Sagrada. "El Director puede enseñar todo lo que le permita el tiempo, su capacidad y las de sus discípulos. Pero los objetos de preferencia son: leer, escribir, los principios de la religión, los de aritmética y geografía. Aquí habla de métodos, aconseja para aprender a escribir el sistema de Carver y para los principios de Historia Sagrada y Religión los catecismos de Fleury y el Padre Astete" según Bohórquez Casallas Luis Antonio (1956) ${ }^{20}$.

En las Escuelas Doctrinales 1789, el Doctor Felipe Salgar, de San Juan Girón, afirmó: “30. Como después de las lecciones de la semana se debe destinar el día sábado para la enseñanza de la doctrina cristiana,

${ }^{19}$ FLEURI ABAD CLAUDE. (1640-1723): Catecismo histórico o Compendio de la Historia Sagrada i de la Doctrina Cristiana. Para Instrucción de los niños, con preguntas, respuestas y lecciones seguidas para leerlas en las escuelas. Traducido del francés al castellano y nuevamente corregido con las licencias necesarias para utilidad de la tierna juventud. Reimpreso en Bogotá en la de José Manuel Galagarza. Año de 1824, p. 109.

BOHÓRQUEZ CASALLAS, Luis Antonio. (1956): La evolución educativa en Colombia Cap.XII. La Educación en la Colonia. Escuela de las primeras letras y cap. XIV la cuestión religiosa de 1850 a 1886, p. 234. 
sería muy de desear que a más de las preguntas ordinarias que se suelen aprender por el Padre Astete, o Reinoso, trajesen los niños algunas lecciones de memoria sacadas del Catecismo Histórico del mismo Abate Fleury. Este sería el modo de que aprendiesen la religión por principios y supiesen dar razón de su creencia conociendo las maravillas de la fe en las diversas edades del mundo. San Juan de Girón, mayo 16 de 1789. Doctor P.D. DEL SALGAR.

- Preguntas y respuestas. Las preguntas están formuladas al final de cada lección para ser respondidas, de acuerdo con el contenido temático desarrollado. No existen las respuestas.

\section{Título de la obra: instrucción moral i religiosa. José María Triana 1851}

Manual para los preceptores de enseñanza primaria e instrucción Moral y Religiosa. Adaptado para las Escuelas de la Provincia de Bogotá. Por RUBINAT I OVALLES. Imprenta del Neogranadino, 1851",29

- Estructura del libro:

1. Carátula y portada

2. Cuadro de errores

3. Prólogo

4. Partes-Secciones

5. Preguntas y respuestas

- Carátula y portada. La función de la carátula hace referencia de presentar, el documento, que se tenga la referencia como el objeto de estudio, como el elemento que identifica el lenguaje, principalmente su ubicación en el tiempo y en el espacio. Se especifica para Preceptores de enseñanza primaria. Así, el catecismo en la portada proporciona los datos necesarios para identificarlo: autor, título de la obra, en donde se imprimió, el respaldo de la autoridad eclesiástica y el año. Si es una traducción al castellano. Se cree que es una de las primeras ediciones, encontrada en los archivos de la Biblioteca Nacional de Colombia.

${ }^{21}$ TRIANA, José María. (1851): INSTRUCCIÓN MORAL I RELIGIOSA. Manual para los preceptores de enseñanza primaria e Instrucción Moral y Religiosa. Adaptado para las Escuelas de la Provincia de Bogotá. Por RUBINAT I OVALLES. Imprenta del Neogranadino. Prólogo, p. I, II, III y IV, p. 95. 
- Cuadro de errores. La expresión: "Páginas -líneas. Dice y debe leerse". Por ejemplo: dice "aucaristiaco", debe leerse "eucaristía". Página 2, línea 24. Uno de los catecismos, que incluye este tipo de información. Ubicado antes de iniciar el estudio del documento.

- Prólogo. Se encabeza con el título "Instruir no educar". Son diversas reflexiones que hace el autor sobre la enseñanza de la religión y la moral. Se especifica: "La instrucción mira solo el desarrollo de la inteligencia; la educación atiende además el desarrollo del cuerpo y al desarrollo del corazón. Hace creído casi generalmente que sólo se necesitaba hacer al hombre sabio, cuando lo que importa más es hacerlo bueno. Pero el atraso i la ignorancia son el veneno del individuo i del pueblo; combatirlos es la misión generosa de los Gobiernos buenos. Para el maestro de escuela, verdadero sacerdote del saber, cuya misión es predicar el evangelio de la sabiduría, nacido del evangelio de la religión; para el maestro de escuela, misionero de la civilización al seno de los pueblos vírgenes, es que se destina este libro que encierra los elementos de las ciencias que más importa conocer, i que ojalá lo fueran desde el uno hasta el otro extremo de nuestro país, hoy libre, i á la vanguardia de los que avanzan á llenar a su fin provincial.

- Partes-Secciones. La estructura del Catecismo en dos partes: primera parte: INSTRUCCIÓN MORAL I RELIGIOSA (Cronología e Historia de la Historia Santa) y la segunda parte: LECCIONES DE CRONOLOGÍA E HISTORIA (Historia Eclesiástica). En la primera parte el catecismo está dividido en cuatro secciones, la primera sección - la existencia de Dios. Pruebas:- Físicas - Morales - Intelectuales-Históricas, los mandamientos de Dios: los diez mandamientos, se reducen al amor de Dios i del prójimo. Los tres primeros se refieren a Dios, miran a Dios, ocupan la primera tabla de la lei de Moisés y los otros siete al prójimo. La segunda sección-Divinidad de Jesucristo, resurrección de Jesucristo: Promesas de Jesucristo; Incredulidad de los Apóstoles i aparición de Jesucristo; Ascensión. La tercera sección-De la Iglesia i de la Tradición: Tradición y la cuarta sección: de los Sacramentos, del bautismo, de la penitencia, de la Eucaristía, del Sacrificio de la Misa.- Direcciones morales para los preceptores. La segunda parte comprende las lecciones la división del tiempo. La Historia 
Sagrada. Los hebreos. La Historia Eclesiástica, la religión cristiana. La Historia Profana, el culto de los ídolos. La Historia Antigua, la destrucción del Imperio Romano, en el año 395 d.d.c.

- Preguntas y respuestas. El método utilizado por el catecismo es de afirmaciones, formuladas en cada sección. Se entienden como dogmas de fe, para ser memorizadas por el Preceptor y el estudiante.

Título de la obra: curso abreviado de religión o verdad y belleza de la religión cristiana. P. Francois Xavier Schouppe S.J. 1883.

Manual acomodado a las Escuelas. Traducido al castellano de la última edición francesa por D. Manuel Pérez Villamil 1883.Tercera edición revisada y corregida. Librería de Ch. Bouret (Paris- México) 587 p.

-Estructura del libro:

1. Aprobaciones. Imprimatur

2. Carátula y portada

3. Advertencia del Editor

4. Prefacio

5. Introducción

6. Partes-Secciones

7. Preguntas y respuestas

- Aprobaciones. Imprimatur. El catecismo posee el imprimatur: +Paulus Goethals. (Excmo. E Illmo.Obispo Prov. Belg. 12 junio 1876. + Mechliniae, 2 julio 1875. +J.B.Lauwers. Vic. General. El Prepósito Provincial de Bélgica, +Paulus y el Vicario General Johannes, Primero de Arlon, 1875.

- Carátula y Portada. El catecismo con valor referencial tiene en la portada la imagen de s.s. León XIII, hecha a lápiz. El documento se ubica en el archivo de la Biblioteca Nacional de Colombia.

- Advertencia del Editor. Se inicia con: "Al ofrecer al público americano esta nueva edición, permítasenos expresar nuestro reconocimiento á su Illmo. Señor Arzobispo de México, otorgando á la obra su alta 
aprobación y dar las gracias al público americano por la excelente acogida que ha hecho á la edición española".

- Prefacio. El Catecismo hace referencia, en esta parte, a lo que precede y prepara al estudio de la materia, a cómo enseñar el contenido de la obra, pensando en la demostración y la explicación de los dogmas. "Para añadir la claridad á solidez hemos adoptado un método sencillo y regular, que juzgamos el más propio, sobre todo mediante una corta explicación oral, para hacer resaltar fácilmente la lógica de las pruebas, el verdadero sentido de los dogmas, y el armonioso conjunto, por fin, de las verdades de la fe y de admirable belleza, llena de encantos". Se afirma: "La Ciencia religiosa debe ser sólida: preciso es que brote de buenas raíces en los corazones juveniles, para que pueda crecer y robustecerse en el curso de la vida y resistir á todas las tempestades. Hay en la enseñanza religiosa dos períodos o grados, que podrían llamarse el grado de la memoria y el de la inteligencia. El primero corresponde á la enseñanza primaria y el segundo á la media y superior". Haciendo importancia en que este curso es para la enseñanza media y superior.

- Introducción. Se inicia este curso de Religión como la parte de la enseñanza que tiene por objeto la Ciencia religiosa. Su importancia excede á la de todos los otros ramos de la sabiduría, porque la religión extiende su influencia no sólo á la vida presente sino á la futura del hombre. Es la única ciencia que encierra una prenda de felicidad para este mundo y para el otro. Se ubican a cada uno de los márgenes de las páginas de la obra, diversas palabras o términos sobre los cuales se desarrollo el contenido del párrafo.

- Partes-Secciones. El catecismo incluye tres partes: la primera la Apologética; la segunda, la Dogmática y la tercera, la moral. La APOLOGÉTICA es la defensa de la verdadera religión contra todos sus .adversarios, sean incrédulos, sean herejes. Encierra los principios racionales de la religión, la demostración de la fe cristiana y de la verdadera Iglesia de Jesucristo y como complemento, la refutación de los principales errores modernos. La verdadera religión. La DOGMÁTICA expone la serie completa de los dogmas de la Fe, después los misterios de Dios y de la creación, hasta el juicio universal, último término de la obra divina en el mundo. Enseña lo que esta religión obliga a creer y la MORAL contiene el cuadro de 
los deberes y las virtudes cristianas. Trata de la ley en general, del decálogo y de los mandamientos de la Iglesia, de los pecados y de las buenas obras, de los sacramentos y de la oración, de las fiestas y de las ceremonias cristianas. Lo que manda practicar".

- Preguntas y respuestas. El Catecismo incluye al final del texto un cuestionario de preguntas por cada parte y cada capítulo. Preguntas que en la primera parte del capítulo 1 , son 62 y del capítulo 2 , son 84. La segunda parte capítulo 1, son 22; del 2 son 14; del 3 son 12; del 4 son 24; del 5 son29; del 6 son 12 ; del 7 son 23 ; del 8 son 12: del 9 son 7; del 10 son 39; del 11 son20; del 12 son 4; del 13 son 13; del 14 son11; del 14 son 11: del 15 son 46; del 16 son 48 : del 17 son 44 y del 18 son 44 . La tercera parte del capítulo 1 son 17; del 2 son 18; del 3 son 126; del 4 son 132; del 5 son 53: del 6 son 6; del 7 son 45; del 8 son18; y del 9 son 50 .

\section{Título de la obra: el catecismo de la doctrina cristiana del Padre Gaspar Asteter, S.J. 1843}

Corregido y aumentado por el Ilustrísimo Señor Arzobispo Doctor José Manuel Mosquera. Nuevamente revisado y aprobado por los Ilustrísimos Señores Doctor Bernardo Herrara, Arzobispo de Bogotá, Doctor J. Pardo Vergara, Obispo de Medellín. Librería Colombiana Bogotá Camacho Roldán y Tamayo. 69 p. con manuscrito del Arzobispo de Bogotá y láminas en tintilla por cada lección.

- Estructura del libro:

1. Aprobaciones. Imprimatur

2. Carátula y portada

3. Advertencia del Editor

4. Prefacio

5. Partes-Secciones

6. Preguntas y respuestas

- Aprobaciones. Imprimatur. El catecismo posee el imprimatur hecho a manuscrito: "por los presentes damos nuestra aprobación a

\footnotetext{
${ }^{22}$ SCHOUPPE, Francois Xavier S.J. (1883): Curso abreviado de Religión o verdad o belleza de la religión Cristiana. Manual acomodado a las escuelas. Traducido al Castellano de la última edición francesa, por el D. Manuel Pérez Villamil - Apologética - Dogmática y Moral. $3^{\text {a }}$. Ed. Revisada y corregida. París y México. Librería de Ch. Bouret. Propiedad del Editor. Introducción, p. X.
} 
la edición del Catecismo de la Doctrina Cristiana por el Padre Gaspar Asteter, S,J, reformado por el Ilustrísimo Señor don Manuel José Mosquera, dado en Roma a 19 de junio de 1896 +Bernardo. Arzobispo de Bogotá. 27 de julio de 1896 +Joaquín Obispo de Medellín.

- Carátula y portada. El Catecismo posee en la carátula el sello efigie del Cordero Pascual en tinta negra sobre un color ocre y la imagen de SS. Papa Pío IX quien otorgó el imprimatur el 28 de octubre de 1841 al Arzobispo de Bogotá Manuel José Mosquera por la gracia de Dios, y de la Santa Sede Apostólica.

- Advertencia del Editor. "La educación religiosa debe revelar a la infancia y explicar a la juventud las verdaderas relaciones que existen entre Dios y nosotros y los deberes sagrados que de ella se derivan; relaciones y deberes conocidos con certidumbre y fielmente expresados en el cristianismo tal como se conservan bajo la custodia de la Iglesia Católica. Inculcad, venerables cooperadores, padres y madres de familia, inculcad con energía y de continuo las partes más importantes de este catecismo a los niños y no las dejéis olvidar a los jóvenes perseverad en una obra difícil como necesaria por cuyo trabajo está reservada una corona de gloria y por cuyo medio únicamente podréis dar buena cuenta de las almas que os ha encomendado nuestro Señor Jesucristo cuya gracia sea siempre con todos vosotros. Amén.

Prefacio. La educación cristiana de los niños es y debe ser siempre uno de los objetos más dignos de la vigilancia pastoral y celo paternal, para instar sobre él con ocasión y sin ella. Todo depende de los primeros años; la edad de la infancia es el tiempo precioso que pasado una vez no tiene otro semejante por el curso de la vida. Esta es una verdad tan clara, que vasta enunciarla para converse ella, como tenemos satisfacción de verlo en padres de familia que se esmeran en formar sus hijos con el conocimiento del verdadero Dios y en la práctica de la religión santa.

- Partes y secciones. El Catecismo se encuentra dividido en una parte preliminar de introducción al estudio de la Religión Católica, compendio de la Doctrina Cristiana y en cuatro partes así: Primera parte de la Doctrina Cristiana, Segunda parte, La 
oración; Tercera parte, los mandamientos y cuarta parte; La gracia y los sacramentos.

- Preguntas y respuestas. El Catecismo incluye por cada lección la pregunta y la respuesta, por ejemplo en la Doctrina Cristiana: pregunta ¿Sois cristiano?. Respuesta, sí, por la gracia de Dios.

Título de la obra: exposición demostrada de la doctrina cristiana. Por el Presbítero Juan Buenaventura Ortiz. 1883

Bogotá. Imprenta de Silvestre y Compañía. Editores y agentes de libro. Empaste: pasta dura, letras doradas al lomo, 309 p.

- Estructura del libro:

1. Aprobaciones. Imprimatur

2. Prólogo

3. Partes-Secciones

4. Preguntas y respuestas

- Aprobaciones. Imprimatur. Autorización del Presidente de los Estados Unidos de Colombia, del Estado Soberano de Cundinamarca, José Eusebio Otálora, en cumplimiento al artículo 66 de la Constitución Política, privilegio 15 años , con la Ley $1^{\mathrm{a}}$ parte $1^{\mathrm{a}}$ tratado $3^{\circ}$ de la Recopilación Granadina, que asegura cierto tiempo, la propiedad de las producciones. Firmado el Secretario del Tesoro, encargado del Despacho de Fomento Alejandro Posada.

Autorización del Arzobispo de Bogotá, 26 de septiembre de 1882 Secretario Joaquín Gómez Otero. "El Señor Vicario General N. 3. Que aunque la obra del Padre Schouppe es de gran importancia, no está sin embargo, tan al alcance de los niños como está.”

Arquidiócesis de Santa Fe de Bogotá. Gobierno eclesiástico, Secretaria, No. 309, Bogotá 27 de septiembre de 1882. "En vista del Censor nombrado para revisar esta obra, nos permitimos que se imprima y la recomendamos para que sirva de texto en la escuelas y colegios de la Arquidiócesis". M. Vicente. Vicente ARBELAEZ. Bogotá, 9 de febrero de 1883. Arzobispo de Bogotá. 
- Prólogo. José Manuel Marroquín. "Explicación sobre la instrucción religiosa, los preceptos morales y las prácticas del Catolicismo, según la religión católica. Nos hemos ensayado nosotros en el catecismo de Schouppe, de que recientemente se ha empezado a hacer uso en algunos Colegios. Pero podemos creer afirmar que hay más teología que puede enseñarse a los principiantes; y que como texto que haya de emplearse en nuestros establecimientos, adolece de los defectos de que tiene que adolecer todas las obras compuestas por sujetos que no posean conocimiento práctico de los que son nuestros colegios y los niños que en ellos estudian. $\mathrm{El}$ autor del presente tratado ha adquirido ese conocimiento enseñando religión por muchos años y justamente se ha decidido a componerlo por que ha tocado con las manos los inconvenientes de los textos que aquí se y han usado. El señor Ortiz halló medio de dejarnos contentos a todos dividiendo sus capítulo en párrafos bastante cortos cada uno de los cuales puede servir de respuesta a una pregunta de las que se hayan formando un cuestionario separado".

- Partes-Secciones. El Catecismo se encuentra estructurado en tres partes:- el DOGMA, LA MORAL y LA ORACIÓN. LA GRACIA Y LOS SACRAMENTOS. Cada uno con sus respectivos capítulos.

- Preguntas y respuestas. Al final del documento se formulan las preguntas por cada una de las partes y de los capítulos.

Título de la obra: gran catecismo católico del Padre José Deharbe S.J. 1895

Su aplicación clara y fundamental con ejemplos escogidos y adaptados a cada tema por el Padre José Deharbe de la Compañía de Jesús, 798 pág. Traducido directamente del alemán por un Sacerdote de la misma Compañía de Jesús.

- Estructura del libro:

1. Carátulas y portada

2. Prólogo

3. Partes-Secciones

4. Preguntas y respuestas 
- Carátula y portada. Imprenta: Sociedad Editorial de San Francisco de Sales (Madrid). Encuadernación en pasta dura, símbolo papal. Color negro, letras doradas, cuatro tomos.

- Prólogo. "En la primera parte de esta obra hemos hecho conocer al Cristiano el fin de su peregrinación por el mundo que es el cielo con sus bienes y delicias, como nos lo enseña nuestra santa Fe. En la segunda parte hemos indicado y señalado el camino por el cual es preciso andar para llegar un día a la Patria celestial y reposar en el seno de Dios. En la tercera parte nos hace conocer los medios que debemos emplear para recibir del cielo. Aquella fuerza y socorros de que necesitamos para conseguir nuestro último fin, que es la felicidad eterna. Censura: Se dijo al principio del CATECISMO, "que para ser felices eran necesarias tres cosas:-la Fe,-la observancia de los Mandamientos y -los Medios de gracia, sin los cuales no podemos creer rectamente, ni observar con fidelidad los Mandamientos".

- Partes-Secciones. Posee índice y apéndice. El texto se encuentra estructurado en cuatro partes: la primera parte: - de la Fe; - la segunda parte: - de los medios para atender la Gracia, y de los Santos Sacramentos, - la tercera parte- de los Mandamientos y - la cuarta parte: - de la oración.

- Preguntas y respuestas. En cada capítulo se enuncian las preguntas y la ubicación de la respuesta correspondiente. Después de cada lección se da una aplicación y al final notas y ejemplos.

Título de la obra: el catecismo de la doctrina cristiana explicado. Por el licenciado D. Santiago José García Mazo. 1845

- Estructura del libro:

1. Aprobaciones, imprimatur

2. Carátulas y portada

3. Prólogo

4. Partes-Secciones

5. Preguntas y respuestas

- Aprobaciones, imprimatur. Autorización del Arzobispo. "Del Excmo. E Illmo. Sr. Obispo de Tuy a los Abades, Arciprestes, Párrocos 
y demás eclesiásticos de su Obispo. 18 de abril de 1838. Fr. Francisco, Obispo de Tuy. Explicaciones del Astete que convienen también al RIPALDA. Magistral de la Santa Iglesia Catedral de Valladolid. 416 pág.

Imprimatur. + Francisco, Obispo de Tuy (Valladolid). Indulgencias. El Emmo. Señor Cardenal Arzobispo de Sevilla concede 100 días de indulgencia y el señor Arzobispo de Burgos; 80 a todos los fieles por cada plana que leyeron u oyeron leer de este Catecismo. Los Obispos de Valladolid, Tuy, Coria y Ávila, Segovia, Santander y Cada hora, 40 días por cada pregunta con su respuesta. -Censura: "La pureza de las Doctrinas contenidas en este pequeño volumen, su claridad y sencillez; el zelo y convicción Cristiana con que está escrito, y que parece comunicarse a los que le leen, le hace el libro más estimado y a propósito para el común de los fieles y muy particularmente, para la Juventud". Boletín oficial 12 de agosto de 1837.

- Carátula y portada. Encuadernación en pasta dura, grabado el símbolo de la cruz, en letras doradas.

- Prólogo. "La Religión Cristiana es tan hermosa, que no es posible dejar de amarla en llegando a conocerla bien. La experiencia de 40 años me ha hecho ver constantemente la verdad. Siempre procure explicarla en las parroquias que estuvieron a mi cargo, y siempre vi que se amaba según se conocía y se practicaba".

- Partes-Secciones. Posee índice y apéndice. El Catecismo se encuentra estructurado en cuatro partes: la primera parte:- de la Doctrina Cristiana, en que se declara el Credo y los artículos de la Fe;-la segunda parte: - de la Doctrina Cristiana en que se declara lo que se ha de pedir y las oraciones de la Santa Madre Iglesia; - la tercera parte: - en que se declara lo que se ha de obrar y la cuarta parte: - en que se declaran los Sacramentos que han de recibir.declaración de la Doctrina Cristiana por Preguntas y Respuestas. Renovación de las renuncias y promesas hechas por el Bautismo. División de la Doctrina Cristiana.

- Preguntas y Respuestas. Al comienzo de cada lección se inicia con una pregunta en cuyo contenido se da respuesta y explicación a la misma. 


\section{CONCLUSIÓN}

En este artículo, en el que se ofrece un análisis básico del uso de los Catecismos para la enseñanza de la religión católica, en el período de la Nueva Granada (1832-1858), y de los Estados Unidos de Colombia (1863-1885), durante el siglo XIX, demuestran una alta influencia de los Teólogos, de los Sacerdotes Jesuitas, como principales autores de los Catecismos y quienes fueron expulsados por el Presidente de la República General José Hilario López 1850. Los Jesuitas regresaron al país en 1859 y fueron nuevamente expulsados por el Presidente de la República Tomás Cipriano de Mosquera en 1863. Retornaran al país por invitación del Presidente de la República Rafael Núñez (1886).

Uno de los hechos significativos y resultado de la investigación fue la ubicación de Catecismos, básicos en la formación de profesionales de la Universidad Nacional de los Estados Unidos de Colombia (1892) Colegio de San Bartolomé y Colegio de Nuestra Señora del Rosario, Universidad Católica de Bogotá (1893). Se creía entonces, que los Catecismos, llegaron a ser obligatorios después de la firma del Concordato en 1887, cuando en realidad los Catecismos, hicieron parte de la formación religiosa de los colombianos desde 1834.

Todos los Catecismos reseñados, manifiestan una gran preocupación por, el método de estudio (la mayéutica, las preguntas y respuestas), para lograr una alta aceptación por parte de los estudiantes y profesores. En su mayoría, registran el IMPRIMATUR sello del Obispo o del Arzobispo, que recomienda su estudio, en algunos casos se permitió elaborar el prólogo al Dr. José Manuel Marroquín o al Dr. Miguel Antonio Caro, quienes años más tarde ejercieron la Presidencia de la República.

Se destaca el papel de la Iglesia Católica y en especial de la Compañía de Jesús, como Instituciones capaces de contribuir con su doctrina a una formación ético-religiosa de los estudiantes colombianos, y del ejercicio de las funciones otorgadas por el Concordato desde el control de los textos de religión, moral, hasta el nombramiento de maestros, o educadores en la fe católica. Los Catecismos analizados, llevan el discurso de la pedagogía católica, la praxis religiosa, sobre cualquier otro aspecto. Algunas de las obras señaladas en este estudio, ubican el número de indulgencias que se ganan al leer y poner en práctica el catecismo. 


\section{FUENTES}

ASTETE, Gaspar S.J. (1896) Catecismo de la Doctrina Cristiana corregido y aumentado por el Ilustrísimo Señor Arzobispo Doctor Manuel José Mosquera. Nuevamente revisado y aprobado por los Ilustrísimos Señores Doctor Bernardo Herrera, Arzobispo de Bogotá y Doctor J. Pardo Vergara Obispo de Medellín. Bogotá. Librería Colombiana Camacho Roldán y Tamayo. Dado en Roma 19 junio de 1896 y 27 de julio de 1896, Medellín.

DECRETO 595 DE 1886 (9 de octubre) Por el cual se organiza la Instrucción Pública Primaria. El Ministro de Instrucción Pública José Domingo Ospina. El Presidente J. M. Campo Serrano. Diario Oficial.

DECRETO 596 DE 1886 (9 de octubre) Sobre la Instrucción Pública Secundaria y Profesional. El Ministro de Instrucción Pública José Domingo Ospina. El Presidente J. M. Campo Serrano. Diario Oficial 1886.

DECRETO 255 DE 1886 (enero 13) Por el cual se organiza provisionalmente la instrucción Pública Primaria. Miguel Casabianca Gobernador Civil y Militar del Estado del Tolima. Neiva. 13 de enero de 1986. Adriano Tribin, Secretario de Gobierno. Diario Oficial N. 6586 del martes 2 de febrero de 1886. Año XXII.

DECRETO 349 de 1892 (31 diciembre) Orgánico de la Instrucción Pública. Ministro de Instrucción Pública, Liborio Zerda.

DECRETO 429 DE 1893 (20 DE ENERO) por el cual se organiza la Instrucción Pública primaria. Diario Oficial No. 9.073 Bogotá, domingo 12 de febrero de 1893.

LEY 106 DE 1880 (23 Agosto) “Que organiza la Instrucción Pública Nacional.” El Presidente de los Estados Unidos de Colombia. Rafael Núñez. El Secretario de Instrucción Pública Rafael Pérez. Publicado Diario Oficial Número 4794, sábado 28 de agosto 1880. Año XVI.

LEY 35 DE 1888 (27 de febrero) "Que aprueba el CONVENIO de 31 de diciembre de 1887 celebrado en la ciudad de Roma, entre el Sumo Pontífice León XIII y el Presidente de la República Rafael NÚÑEZ. Publicado Diario Oficial Número 7311. Año XXIV. Bogotá, sábado 3 de marzo de 1888.

MINISTERIO DE INSTRUCCIÓN PÚBLICA. (1893): Reglamento para las Escuelas Primarias. 31 de julio de 1893. Edición del folleto de 47 páginas. Bogotá, Imprenta de la Luz.

RESOLUCIÓN del 15 de junio de 1888. El Ministro J. Casas Rojas. Gobierno Ejecutivo Nacional Peña Negra, 16 de junio de 1888. Aprobado Rafael Núñez. Bogotá, junio 17 de 1888. 
RESOLUCIÓN Agosto 19 de 1887. Ministro de Instrucción Pública J. Domingo Ospina C. Diario Oficial N. 7150 del sábado 27 agosto de 1887. Año XXIII.

SCHOUPPE, Francois Xavier S.J. (1885): Curso abreviado de Religión o verdad o belleza de la religión Cristiana. Manual acomodado a las escuelas. Traducido al Castellano de la última edición francesa, por el D. Manuel Pérez Villamil-Apologética - Dogmática y Moral. $3^{a}$. Ed. Revisada y corregida. París y México. Librería de Ch. Bouret. Propiedad del Editor.

TRIANA, José María. (1851): Manual para los preceptores de enseñanza primaria. Instrucción moral i religiosa, adaptado para las Escuelas de la Provincia de Bogotá. Bogotá, Imprenta del Neogranadino. Por Rubinat i Ovalles.

\section{REFERENCIAS}

BÁEZ OSORIO, Myriam. (2004): Las Escuelas Normales y el Cambio Educativo en los Estados Unidos de Colombia en el período Radical 1870-1886. Tunja, Impresión: Publicaciones e Imprenta UPTC.

BLANCO Y SÁNCHEZ, Rufino. (1909): Pestalozzi su vida y su obra. El sistema. El método Pestalozzi - Pestalozzi en España. Madrid, Imprenta de la Revista de ARCHIVOS. Infantes.

BOHÓRQUEZ CASALLAS, Luis Antonio. (1956): La evolución educativa en Colombia. Bogotá. Publicaciones Cultural Colombiana Ltda.

CASAS ROJAS, Jesús. (1888): Ministro de Instrucción Pública Programa de Religión $y$ de Moral para los establecimientos de Instrucción Pública.

FLEURI, Abad. (1824): Catecismo histórico o Compendio de la Historia Sagrada i de la Doctrina Cristiana. Para Instrucción de los niños, con preguntas, respuestas y lecciones seguidas para leerlas en las escuelas. Traducido del francés para utilidad de la tierna juventud. Bogotá, Reimpreso en la de José Manuel Galagarza.

GRANADOS, Rafael María. S.J. (1963): Historia de Colombia. La Independencia y la República. Texto adaptado al Programa Oficial de sexto año. Novena edición. Medellín, Editorial Bedout. 
HenAO Y ARRUBLA. (1952): Historia de Colombia. Para la enseñanza secundaria. Séptima edición corregida y aumentada. Bogotá, Impreso en los Talleres de la Librería Voluntad, S.A.

P. LASALDE, Carlos. (1911): Manual de Pedagogía o sea exposición de los principios fundamentales de la Educación y Métodos de enseñanza. $2^{a}$ ed. Alemania, Friburgo de Brisgovia Ed. Herder y Cía. Libreros Editores Pontificios.

DUARTE ACERO, Jorge Enrique; RIVEROS BONILLA, Martha Consuelo. (2011): "El uso de los catecismo en la enseñanza de la religión católica en el período neogranadino y de los Estados Unidos de Colombia. 1831-1886" en: Revista Historia de la Educación Latinoamericana N. 16, Tunja, Universidad Pedagógica y Tecnológica de Colombia, RUDECOLOMBIA, SHELA- HISULA pp. 119- 150 